\title{
PRODUÇÃO DE SULFETO DE MOLIBDÊNIO DE ALTA PUREZA
}

\author{
L.Z.S. SOUZA ${ }^{1}$, L.R.P. DE ANDRADE LIMA \\ ${ }^{1}$ Universidade Federal da Bahia, Programa de Pós-Graduação em Engenharia Industrial \\ ${ }^{2}$ Universidade Federal da Bahia, Departamento de Ciência e Tecnologia dos Materiais \\ E-mail para contato: lelo@ufba.br
}

\begin{abstract}
RESUMO - O Brasil não possui reservas oficias de sulfeto de molibdênio (molibdenita), mas a ocorrência de Carnaíba vem sendo explorada e concentrada por flotação de forma artesanal há vários anos, mas o concentrado de sulfeto molibdênio produzido tem baixo teor devido á presença de outras espécies hidrofóbicas que estão associadas á molibdenita nesta região. Neste estudo foram feitos testes de flotação em laboratório usando silicato de sódio ou dextrina como depressor dos silicatos, óleo de pinho ou metil isobutil carbinol, como espumante e querosene como coletor. Os resultados da flotação indicam que na faixa granulométrica 100 malhas a molibdenita está totalmente liberada. Os testes de flotação empregando silicato de sódio e querosene permitiram uma alta recuperação na coleta do sulfeto de molibdênio e a produção de concentrado com teor acima de $58 \%$ de molibdênio.
\end{abstract}

\section{INTRODUÇÃO}

O sulfeto de molibdênio possui várias aplicações sendo empregado como lubrificante sólido e em micro-eletrônica, assim como na produção de molibdênio metálico e oxido de molibdênio para ser usado na produção de ligas metálicas e pigmentos. O sulfeto de molibdênio ou molibdenita é encontrado em diversos tipos de depósito mineral incluindo pegmatitos e dique aplito, que geram cristais de pureza elevada (Gupta, 1992). Embora o Brasil não tenha reservas oficiais de molibdenita há uma ocorrência em Carnaíba, Bahia, que vem sendo tratada de forma semi-industrial (Silva e Moreira, 2006).

Braga et al. (2011) e Braga e Santos (2012) avaliaram a prática do beneficiamento utilizada na região de Carnaíba (BA) e realizaram a caracterização do concentrado e do rejeito do processo. Na caracterização química foi verificado que o minério apresentava teores de molibdênio variando de 0,21 a 1,73\% $\mathrm{MoO}_{3}$. Foi identificado no minério a presença de altos teores de $\mathrm{Mg}$ e $\mathrm{Al}$. A caracterização mineralógica mostrou que alem da molibdenita os principais minerais encontrados no minério de Carnaiba são: biotita, clinocloro, talco e albita. Para a avaliação dos métodos de beneficiamento usados na região foram coletas amostras de minérios e rejeitos e concentrados nos diversas áreas. Foram realizados testes de flotação da molibdenita em laboratório usando óleo de pinho como espumante e duas etapas (desbaste e limpeza). Os ensaios produziram concentrados com um teor de $25 \%$ de molibdênio na etapa de desbaste e $45 \%$ na etapa de limpeza. A recuperação global do processo foi de $85 \%$. Estes autores notaram que duas unidades de flotação artesanal produziram 


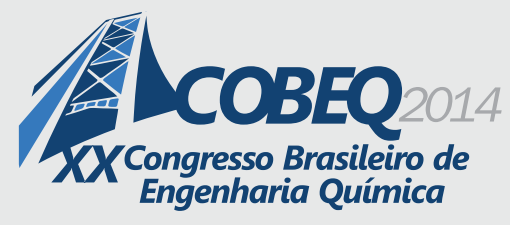

19 a 22 de outubro de 2014
Florianópolis/SC

concentrados com teor de molibdênio abaixo do esperado, cerca de 20\%, devido a presença de talco que flota junto com a molibdenita e dilui o concentrado.

Santana e de Andrade Lima (2013) investigaram o efeito da granulometria na recuperação e no teor do concentrado de molibdenita da região de Carnaíba (BA). Neste estudo utilizaram duas amostras, sendo a primeira o rejeito de estudos preliminares e a segunda um minério fresco. A caracterização química apresentou teores variando de $(0,15$ a $0,22 \%$ Mo para a primeira amostra e 0,46 a 1,82 \% Mo para a segunda amostra). A caracterização mineralógica mostrou que os principais minerais de ganga são: albita, biotita, flogopita, clinocloro, muscovita e quartzo. As flotações da primeira amostra foram feitas nas faixas granulométricas (60/100 e 100/200 malhas Tyler) utilizaram querosene como coletor, óleo de pinho ou glicerol como espumantes e silicato de sódio como depressor. Foram produzidos concentrados com teor de molibdênio de ate 4,2\% e recuperação de ate $61,2 \%$, quando foi usado óleo de pinho como espumante e silicato de sódio como depressor. Na avaliação da flotação da segunda amostra com óleo de pinho como espumante e silicato de sódio como depressor, nas faixas granulométricas (35/48 a 100/200 malhas), foram obtidos concentrados com teor de molibdênio de até $25 \%$ e recuperação de cerca de $100 \%$. Os resultados indicaram que a molibdenita esta liberada para um tamanho inferior a 60 malhas.

de Souza e de Andrade Lima (2013) estudando os cristais de molibdenita encontrado na região da Carnaíba constataram a presença de micas no interior dos cristais o que reduz o teor médio de molibdênio neste material. Foram encontrados teores de 38 a 42\% de Mo, o que é inferior ao valor de 60\% de Mo encontrado na molibdenita pura. Como a molibdenita e naturalmente hidrofóbica, o presente estudo tem como objetivo detalhar a concentração por flotação de sulfeto de molibdênio da Carnaíba visando à produção de sulfeto de molibdênio de alta pureza.

\section{METODOLOGIA}

Neste estudo foram usadas duas amostras da molibdenita disseminada, ambas oriundas da Serra de Carnaíba. A primeira amostra correspondente a uma amostra rica em micas, análoga a que vem sendo tratada na região devido a pequena dureza deste material. A segunda amostra corresponde a amostra dois discutida por Santana e de Andrade Lima (2013). As amostra foram moídas, homogeneizadas, classificadas e posteriormente amostradas. Para a primeira amostra foram consideradas as faixas granulométricas 48/60, 60/100, 100/150, 150/200 e 200/325 malhas e para a segunda amostra as faixas granulométricas 35/48, 48/60, 60/100, 100/150 e 150/200 malhas foram consideradas. A composição química e a mineralógica das duas amostras foram obtidas através da espectrometria de fluorescência de raios X (XRF) com o equipamento Nilton XL3T e difração de raios X (XRD) pelo equipamento Shimadzu XRD - 6000.

Na flotação utilizou-se óleo de pinho (concentração $30 \mathrm{~g} / \mathrm{t}$ ) ou metil isobutil carbinol como espumante, silicato de sódio (concentração de 330g/t) ou dextrina como depressor. Após a flotação os sólidos foram secos em estufa a $100^{\circ} \mathrm{C}$ e analisados usando XRF. Os ensaios de flotação foram realizados em célula de laboratório, equipamento Denver com recipiente de um litro e meio. Nestes ensaios utilizou-se uma rotação de 900 RPM, pH natural da polpa, e percentagem de sólidos em torno de 31\%. Em um ensaio de concentração de um rejeito de flotação foi usado um tubo de Hallimond 
modificado. Os ensaios de flotação com a segunda amostra do minério disseminado foram realizados de forma análoga ao anterior, mas foi usado querosene como coletor, em alguns testes.

\section{RESULTADOS E DISCUSSÃO}

As Figuras 1a e 1b apresentam os difratogramas da amostras 1 e 2. Observa-se que as amostras são constituídas predominantemente por quartzo $\left(\mathrm{SiO}_{2}\right)$ e por minerais do grupo dos filossilicatos como a flogopita $\mathrm{KMg}_{3} \mathrm{Si}_{3} \mathrm{AlO}_{10}(\mathrm{~F}, \mathrm{OH})_{2}$, biotita $\left(\mathrm{K}\left(\mathrm{Mg}, \mathrm{Fe}^{2+}\right)_{3}\left(\mathrm{Al}, \mathrm{Fe}^{3+}\right) \mathrm{SiO}_{3} \mathrm{O}_{10}(\mathrm{OH}, \mathrm{F})_{2}\right)$ e albita $\left(\mathrm{Na}_{1.0^{-0.9}} \mathrm{Ca}_{0.0^{-} 0.1} \mathrm{Al}_{1.0^{-} 1.1} \mathrm{Si}_{3 \cdot 0-2 \cdot 9} \mathrm{O}_{8}\right)$. Nota-se também em pequenas proporções do mineral do grupo da clorita, o clinocloro (5MgO. $(\mathrm{Al}, \mathrm{Cr})_{2} \mathrm{O}_{3.3} \mathrm{SiO}_{2} .4 \mathrm{H}_{2} \mathrm{O}$ ) e também molibdenita $\left(\mathrm{MoS}_{2}\right)$. A Figura $1 \mathrm{~b}$ indica que a amostra 2 tem uma menor quantidade de minerais do grupo dos filossilicatos, como a biotita e muscovita.

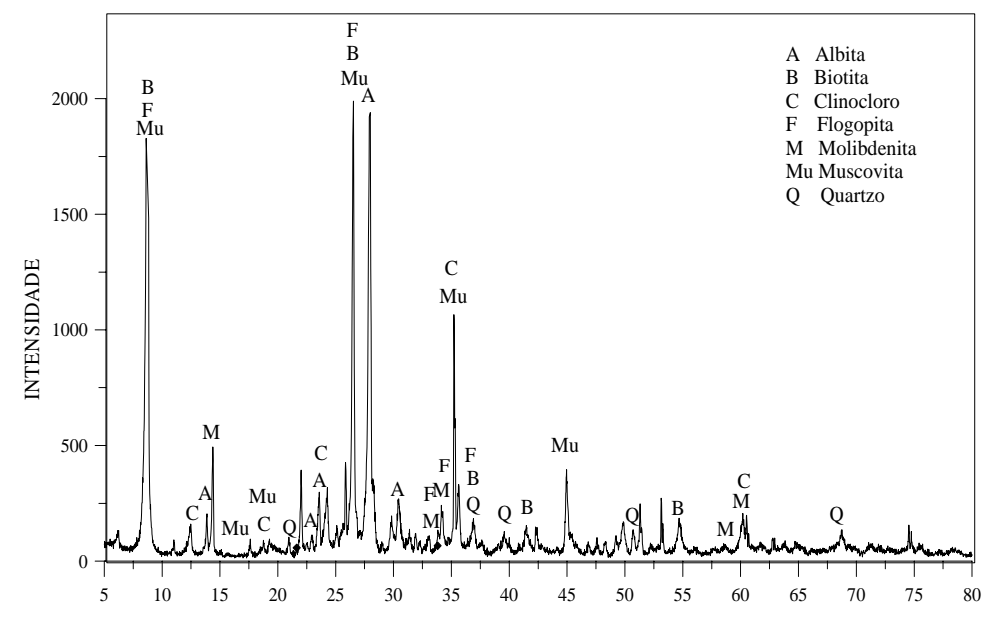

(a)

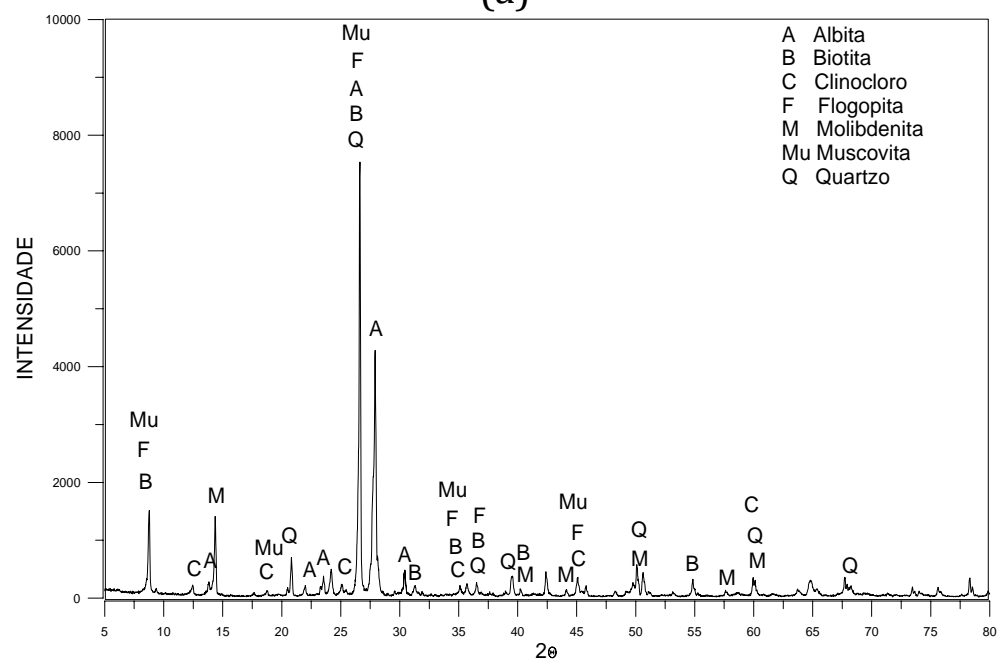

(b)

Figura 1 - Difração de raios X de minérios de Carnaíba. a) Amostra 1, b) Amostra 2. 
A avaliação da liberação da molibdenita (não detalhada neste trabalho) mostrou que a molibdenita esta liberada no tamanho inferior a 100 malhas na amostra 1 e em tamanho inferior em 60 malhas na amostra 2.

A Tabela 1 apresenta os resultados dos ensaios de flotação realizados com a amostra 1 foi avaliado o efeito da granulometria, nota-se que os teores de molibdênio no concentrado são inferiores a 9\%, o que está associado a uma baixa seletividade. Verifica-se que o melhor resultado foi o ensaio 2, que produziu um concentrado com teor de molibdênio de $8,41 \%$ e recuperação de $96 \%$. O ensaio análogo realizado com a dextrina como depressor de silicatos no lugar do silicato de sódio e metil isobutil carbinol como espumante no lugar do óleo de pinho, em pH alcalino teve uma recuperação de $100 \%$ mas produziu um concentrado com apenas 8,35\% de molibdênio isso mostra que a seletividade não foi melhorada. O ensaio 1 mostra que não foi possível flotar a molibdenita, pois neste tamanho a molibdenita não está liberada. As Figuras 2a e 2b sumarizam esses resultados.

Tabela 1 - Resultados da flotação da amostra 1.

\begin{tabular}{|c|c|c|c|c|c|}
\hline Ensaios & $\begin{array}{c}\text { Faixa Granulométrica } \\
\text { (malha Tyler) }\end{array}$ & Reagentes & & $\begin{array}{c}\text { Teor Mo } \\
(\%)\end{array}$ & $\begin{array}{c}\text { Massa } \\
(\mathrm{g})\end{array}$ \\
\hline \multirow[t]{2}{*}{1} & \multirow[t]{2}{*}{$48 / 60$} & Silicato de sódio & Alimentação & 0,30 & 335,68 \\
\hline & & Óleo de pinho & Rejeito & 0,24 & 329,85 \\
\hline \multirow[t]{4}{*}{2} & \multirow[t]{4}{*}{$60 / 100$} & Silicato de sódio & Alimentação & 0,30 & 332,87 \\
\hline & & Óleo de pinho & $1^{\circ}$ Concentrado & 8,41 & 11,40 \\
\hline & & & $2^{\circ}$ Concentrado & 0,26 & 12,47 \\
\hline & & & Rejeito & 0,02 & 303,17 \\
\hline \multirow[t]{4}{*}{3} & \multirow[t]{4}{*}{$100 / 150$} & Silicato de sódio & Alimentação & 0,41 & 335,72 \\
\hline & & Óleo de pinho & $1^{\circ}$ Concentrado & 7,33 & 15,97 \\
\hline & & & $2^{\circ}$ Concentrado & 0,37 & 11,84 \\
\hline & & & Rejeito & 0,04 & 300,74 \\
\hline \multirow[t]{4}{*}{4} & \multirow[t]{4}{*}{$150 / 200$} & Silicato de sódio & Alimentação & 0,50 & 334,72 \\
\hline & & Óleo de pinho & $1^{\circ}$ Concentrado & 8,87 & 15,36 \\
\hline & & & $2^{\circ}$ Concentrado & 0,73 & 20,17 \\
\hline & & & Rejeito & 0,04 & 286,08 \\
\hline \multirow[t]{4}{*}{5} & \multirow[t]{4}{*}{$200 / 325$} & Silicato de sódio & Alimentação & 0,61 & 335,15 \\
\hline & & Óleo de pinho & $1^{\circ}$ Concentrado & 5,00 & 33,86 \\
\hline & & & $2^{\circ}$ Concentrado & 0,31 & 24,91 \\
\hline & & & Rejeito & 0,02 & 267,34 \\
\hline
\end{tabular}

A recuperação para o primeiro concentrado da flotação do minério aumenta proporcionalmente em relação ao tamanho. Os resultados indicam que a recuperação foi de cerca de $100 \%$ na faixa granulométrica abaixo de 100 malhas, pois a molibdenita já esta liberada nesse tamanho. A Figura 4 sumariza esses resultados. 


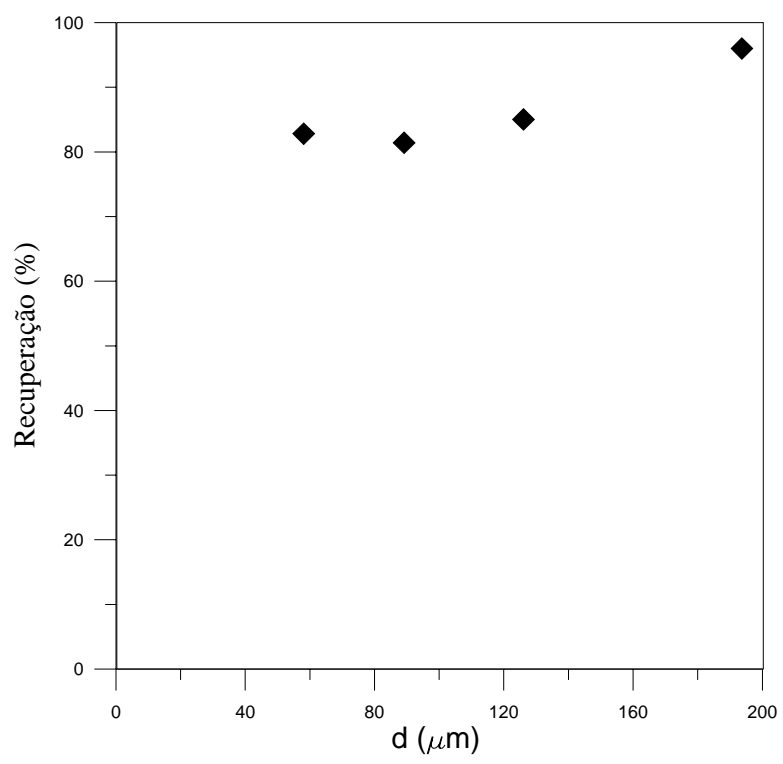

(a)

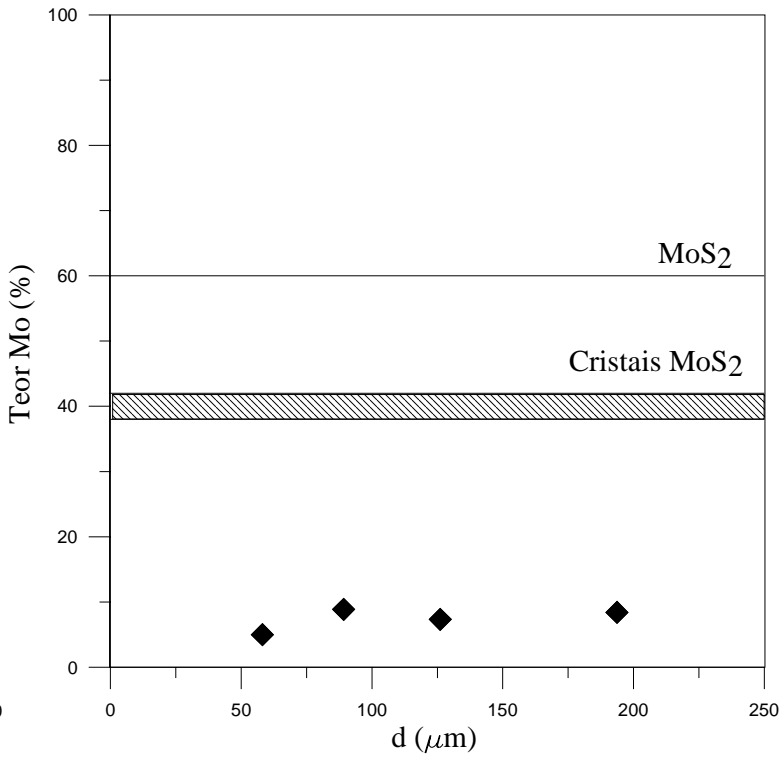

(b)

Figura 2 - Recuperação (a) e teor (b) do molibdênio versus o tamanho na flotação da amostra 1.

A Tabela 2 apresenta os resultados da flotação realizados com a amostra 2, para a qual foi avaliado o efeito granulometria. Nota-se que os teores do concentrado de molibdênio são superior a $30 \%$. Os melhores resultados da flotação com minério ocorreram nos ensaios 7 e 8 . No ensaio 6, a molibdenita não está totalmente liberado. A molibdenita está liberada no ensaio 8. As Figuras 3a e 3b sumarizam esses resultados. Nota-se que a recuperação é menor na faixa granulométrica 100/150 malhas $(126,09 \mu \mathrm{m})$. Entretanto, para as faixas granulométricas 48/60malhas $(273,86 \mu \mathrm{m})$ e $60 / 100$ malhas $(193,65 \mu \mathrm{m})$ tem os melhores resultados de recuperação de cerca de $100 \%$, pois nestas faixas a molibdenita está liberada. Nas faixas 100/150 malhas $(126,09 \mu \mathrm{m})$ e 150/200 malhas $(89,16 \mu \mathrm{m})$ tem uma redução da recuperação do molibdênio, pois a ganga é hidrofobizada nas frações finas. Em ensaio análogo ao 7, mas usando querosene como coletor, o teor de molibdênio no concentrado foi de $52,32 \%$, o que indica uma melhor seletividade.

A concentração da amostra 2 na presença de querosene foi avaliada. A Tabela 3 apresenta esses resultados. Nota-se melhores resultados nos ensaios realizados com silicato de sódio como depressor, óleo de pinho como espumante e querosene como coletor, que produziu concentrados de sulfeto de molibdênio de alta pureza. Os melhores resultados da flotação do minério ocorreram nos ensaios 11 e 12 como teores de concentrado de molibdênio respectivamente de 58,15\% e 46,06 com recuperação cerca de $100 \%$. No ensaio 15 o teor do concentrado de molibdênio 15,90\%, ocorreu devido a ganga hidrofobizar nas frações finas. No ensaio 13 foi feito micro flotação, no qual o teor do concentrado de 2,07 foi para 28,16\% de molibdênio. O concentrado por flotação alcançou teor de 58,15\% de molibdênio. A Figura 4 sumariza esses resultados. 
. Tabela 2 - Resultados da flotação da amostra 2.

\begin{tabular}{|c|c|c|c|c|c|}
\hline Ensaios & $\begin{array}{c}\text { Faixa Granulométrica } \\
(\#)\end{array}$ & Reagentes & & $\begin{array}{l}\text { Teor } \\
(\%)\end{array}$ & $\begin{array}{l}\text { Massa } \\
(\mathrm{g})\end{array}$ \\
\hline \multirow[t]{3}{*}{6} & $35 / 48$ & Silicato de sódio & Alimentação & 0,46 & 317,97 \\
\hline & & Óleo de pinho & $1^{\circ}$ Concentrado & 30,17 & 1,95 \\
\hline & & & Rejeito & 0,35 & 303,50 \\
\hline \multirow[t]{4}{*}{7} & $48 / 60$ & Silicato de sódio & Alimentação & 0,72 & 320,90 \\
\hline & & Óleo de pinho & $1^{\circ}$ Concentrado & 21,65 & 10,94 \\
\hline & & & $2^{\circ}$ Concentrado & 2,83 & 2,50 \\
\hline & & & Rejeito & 0,08 & 300,27 \\
\hline \multirow[t]{4}{*}{8} & $60 / 100$ & Silicato de sódio & Alimentação & 0,96 & 362,56 \\
\hline & & Óleo de pinho & $1^{\circ}$ Concentrado & 24,36 & 13,90 \\
\hline & & & $2^{\circ}$ Concentrado & 1,62 & 8,59 \\
\hline & & & Rejeito & 0,03 & 329,38 \\
\hline \multirow[t]{4}{*}{9} & $100 / 150$ & Silicato de sódio & Alimentação & 1,46 & 346,03 \\
\hline & & Óleo de pinho & $1^{\circ}$ Concentrado & 19,54 & 19,97 \\
\hline & & & $2^{\circ}$ Concentrado & 1,44 & 20,07 \\
\hline & & & Rejeito & 0,03 & 299,50 \\
\hline \multirow[t]{4}{*}{10} & $150 / 200$ & Silicato de sódio & Alimentação & 1,82 & 415,12 \\
\hline & & Óleo de pinho & $1^{\circ}$ Concentrado & 10,03 & 62,30 \\
\hline & & & $2^{\circ}$ Concentrado & 0,63 & 35,58 \\
\hline & & & Rejeito & 0,02 & 311,00 \\
\hline
\end{tabular}

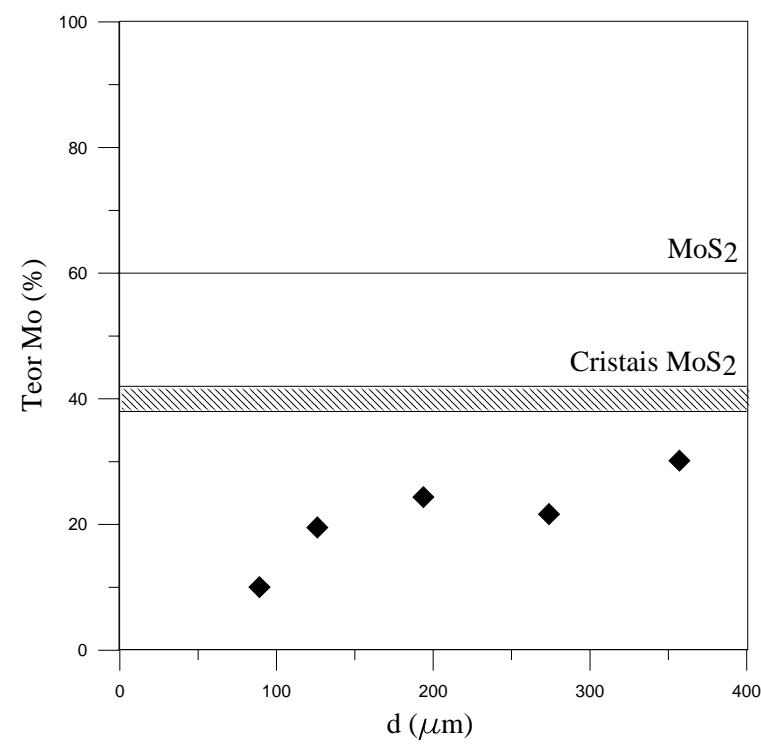

(a)

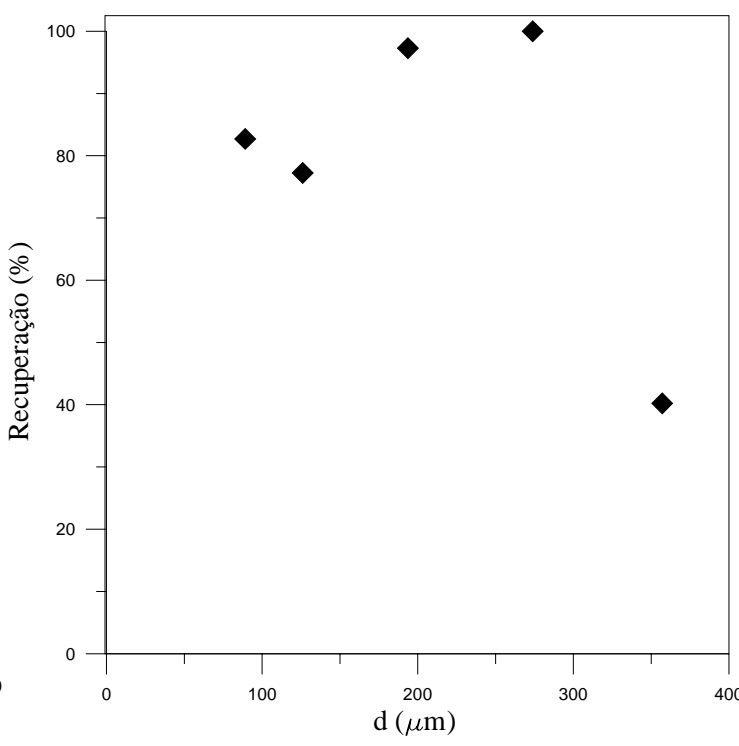

(b)

Figura 3 - Recuperação (a) e teor (b) do molibdênio versus o tamanho na flotação da amostra 2. 
Tabela 3 - Resultados da flotação da amostra 2 com querosene.

\begin{tabular}{|c|c|c|c|c|c|}
\hline Ensaios & $\begin{array}{c}\text { Faixa Granulométrica } \\
(\#)\end{array}$ & Reagentes & & $\begin{array}{r}\text { Teor } \\
(\%)\end{array}$ & $\begin{array}{c}\text { Massa } \\
(\mathrm{g})\end{array}$ \\
\hline \multirow[t]{3}{*}{11} & $35 / 48$ & Silicato de sódio & Alimentação & 0,52 & 320,00 \\
\hline & & Óleo de pinho & $1^{\circ}$ Concentrado & 58,15 & 2,64 \\
\hline & & Querosene & Rejeito & 0,32 & 308,11 \\
\hline \multirow[t]{4}{*}{12} & $48 / 60$ & Silicato de sódio & Alimentação & 0,70 & 289,54 \\
\hline & & Óleo de pinho & $1^{\circ}$ Concentrado & 46,06 & 5,59 \\
\hline & & Querosene & $2^{\circ}$ Concentrado & 8,28 & 1,20 \\
\hline & & & Rejeito & 0,05 & 277,63 \\
\hline \multirow[t]{5}{*}{13} & $60 / 100$ & Silicato de sódio & Alimentação & 0,91 & 362,75 \\
\hline & & Óleo de pinho & $1^{\circ}$ Concentrado & 2,07 & 13,40 \\
\hline & & Querosene & $2^{\circ}$ Concentrado & 13,51 & 2,09 \\
\hline & & & Rejeito & 0,05 & 338,24 \\
\hline & & & $\begin{array}{c}\text { Flotação do } \\
\text { Rejeito }\end{array}$ & 28,16 & 2,33 \\
\hline \multirow[t]{4}{*}{14} & $100 / 150$ & Silicato de sódio & Alimentação & 1,36 & 323,61 \\
\hline & & Óleo de pinho & $1^{\circ}$ Concentrado & 26,07 & 16,18 \\
\hline & & Querosene & $2^{\circ}$ Concentrado & 2,44 & 11,07 \\
\hline & & & Rejeito & 0,44 & 287,64 \\
\hline \multirow[t]{4}{*}{15} & $150 / 200$ & Silicato de sódio & Alimentação & 1,82 & 412,17 \\
\hline & & Óleo de pinho & $1^{\circ}$ Concentrado & 15,90 & 39,18 \\
\hline & & Querosene & $2^{\circ}$ Concentrado & 16,62 & 19,09 \\
\hline & & & Rejeito & 0,06 & 346,52 \\
\hline
\end{tabular}

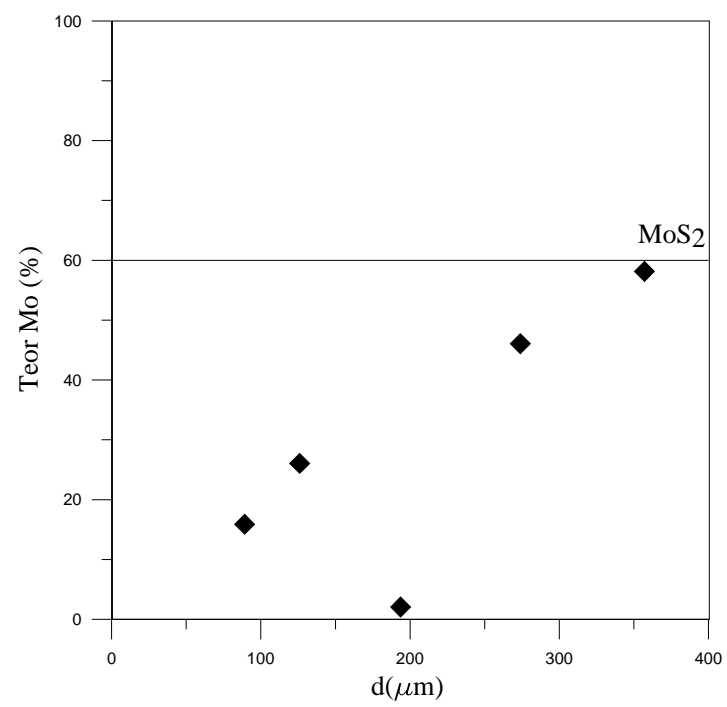

Figura 4 - Recuperação e teor do molibdênio na flotação da amostra 2 com querosene. 


\section{CONCLUSÕES}

Este trabalho utilizou duas amostras de minério da região de Carnaíba (Bahia) visando avaliar a possibilidade de produção de sulfeto de molibdênio de alta pureza por flotação. Os ensaios de concentração por flotação realizados com uma amostra rica em micas e com sulfeto de molibdênio disseminado geraram concentrados com teor de molibdênio de cerca de 9\%. Os resultados da flotação de uma amostra com teores intermediários de micas usando silicato de sódio como depressor dos silicatos e óleo de pinho como espumante geraram concentrados com teor de molibdenita de cerca de 25\%. Este material quando flotado com silicato de sódio, óleo de pinho e querosene como coletor produziu concentrado de alta pureza com teor de molibdênio de 58,15\%. Tendo em vista que o teor de molibdênio nos cristais puros de molibdenita é de $60 \%$ a concentração por flotação de certos minérios da região de Carnaíba pode gerar concentrados de molibdenita de elevado teor.

\section{AGRADECIMENTOS}

O Conselho Nacional de Desenvolvimento Cientifico e Tecnológico (CNPq) é agradecido pelo suporte financeiro a este estudo através do projeto número 550294/2011-2 e de bolsa de pesquisador para L.R.P. de Andrade Lima (projeto número: 302024/2011-5). A Coordenação de Aperfeiçoamento de Pessoal de Nível Superior (CAPES) e o Programa de Pós-Graduação em Engenharia Industrial da Universidade Federal da Bahia são agradecidos pela concessão de uma bolsa de mestrado para L.Z.S. Souza. O laboratório do Grupo de Processos e Tecnologia (PROTEC-UFBA) é agradecido pela realização das difrações de raios $\mathrm{X}$.

\section{REFERÊNCIAS}

BRAGA, P.F.A., CHAVES, A.P., LUZ, A.B. Análise crítica do processo de beneficiamento mineral utilizado na recuperação de molibdenita da Serra de Carnaiba, Ba. Anais do XXIV Encontro Nacional de Tratamento de Minérios e Metalurgia Extrativa, 2011.

BRAGA, P.F.A., SANTOS, F.V.C. Separabilidade de minerais hidrofóbicos por flotação (molibdenita e talco), Anais da XX Jornada de Iniciação Científica CETEM, 2012.

GUPTA, C.K., Extractive Metallurgy of Molybdenum, CRC Press, Boca Raton, p.87-96, 1992.

SANTANA, L.Z.; DE ANDRADE LIMA, L.R.P. Flotação da molibdenita disseminada de Carnaíba (Bahia): Efeito da granulometria. Anais do XXV Encontro Nacional de Tratamento de Minérios $e$ Metalurgia Extrativa, 2013.

SILVA, R.W.S., MOREIRA, M.D. Esmeralda de Carnaíba, Bahia: geologia e desenvolvimento do garimpo, CBPM, Série arquivos abertos, n²5, Salvador, 2006.

SOUZA, A.C.; DE ANDRADE LIMA, L.R.P. Produção de molibdênio metálico a partir da molibdenita de Carnaíba (Bahia). Anais do XXV Encontro Nacional de Tratamento de Minérios e Metalurgia Extrativa, p. 438-445, 2013. 